\title{
MÍDIAS SOCIAIS, EM TEMPOS DE PANDEMIA, PARA O COMPARTILHAMENTO DE CONHECIMENTOS DE ENFERMAGEM DE REABILITAÇÃO
}

\section{REDES SOCIALES, EN TIEMPOS PANDÉMICOS, PARA COMPARTIR EL CONOCIMIENTO DE ENFERMERÍA DE REHABILITACIÓN}

\author{
SOCIAL MEDIA, IN TIMES OF PANDEMIC, FOR SHARING OF KNOWLEDGE IN NURSING REHABILITATION
}

DOI 10.33194/rper.2020.v3.s2.5.5786 | Submetido 01.06.2020 | Aprovado 15/11/2020

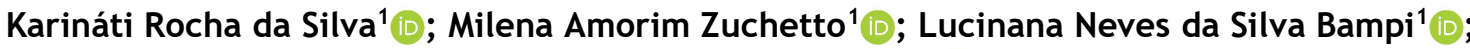 \\ Soraia Dornelles Schoeller ${ }^{1} \mathbb{D}$ \\ 1 - Universidade Federal de Santa Catarina
}

\section{RESUMO}

A Pandemia tem gerado a necessidade de reinventar a maneira de compartilhar conhecimentos, isto posto, as mídias sociais se configuram como uma alternativa para proporcionar disseminação de saberes, visando reduzir as barreiras que obstaculizam a valorização da enfermagem de reabilitação no contexto brasileiro. 0 estudo objetiva compreender o impacto do uso da mídia social, em tempos de pandemia, como instrumento para compartilhar conhecimentos sobre enfermagem, saúde e reabilitação.

O método de Análise Exploratória de Redes Sociais permite a definição, manipulação, determinação de características estruturais e inspeção visual da mídia social.

Os resultados expressam que a mídia digital impacta no compartilhamento de conhecimentos, desafiando o distanciamento social e o cenário de tristeza mundial.

Concluímos que a enfermagem necessita reabilitar-se para o futuro da saúde e da tecnologia, abrindo suas reflexões sobre cuidado com o olhar digital e acessível.

Descritores: enfermagem de reabilitação, mídias sociais, internet, pandemias

\section{RESUMEN}

La pandemia ha generado la necesidad de reinventar una forma de compartir conocimiento, dicho eso, las redes sociales están configuradas como una alternativa para difundir conocimiento, con el objetivo de reducir las barreras; que dificultan la valorización de la enfermería de rehabilitación en el contexto brasileño. El estudio tiene como objetivo comprender el impacto del uso de las redes sociales, en tiempos de pandemia, como un instrumento para dar conocimientos sobre enfermería, salud y rehabilitación.

El método de Análisis Exploratorio de Redes Sociales permite la definición, manipulación, determinación de características estructurales e inspección visual de las redes sociales.

Los resultados expresan que los medios digitales impactan en el intercambio de conocimiento, desafiando la distancia social y el escenario de la tristeza global.

Concluimos que la enfermería necesita rehabilitarse para el futuro de la salud y la tecnología, abriendo sus reflexiones sobre la atención con un aspecto digital y accesible.

Palabras clave: enfermería de rehabilitación; medios de comunicación sociales; internet; pandemias

\section{ABSTRACT}

The pandemic has generated the need to reinvent the way we share knowledge, that said, social media is configured as an alternative to provide dissemination of knowledge, aiming to reduce the barriers that difficult the valorization of rehabilitation nursing in the Brazilian context. The study aims to understand the impact of using social media, in times of pandemic, as an instrument to share knowledge about nursing, health and rehabilitation.

The Exploratory Social Network Analysis method allows the definition, manipulation, determination of structural characteristics and visual inspection of social media.

The results express that the digital media impacts on the sharing of knowledge, challenging social distance and the scenario of global sorrow.

We conclude that nursing needs to rehabilitate itself for the future of health and technology, opening its reflections on care with digital and accessible look. 
Keywords: rehabilitation nursing; social media; internet; pandemics

\section{INTRODUÇÃO}

A enfermagem é uma profissão que possui dois eixos principais: a ciência, considerando sua contribuição para produção acadêmica; e as relações sociais e sensoriais, uma vez que busca a satisfação das necessidades básicas através do cuidado( ${ }^{(1)}$. Este segundo eixo esteve fortemente presente na história da enfermagem desde o princípio. Em meados do século 18 há o início da cientificação da Enfermagem, onde as primeiras pesquisas empíricas na profissão já começaram a ser desenvolvidas por Florence Nightingale ${ }^{(2)}$.

Com o passar dos anos, a enfermagem foi se diferenciando em especialidades para aprofundar conhecimentos de cada necessidade humana. Um exemplo de especialidade é a Enfermagem de Reabilitação, uma área de conhecimento que tem por finalidade maximizar as potencialidades dos indivíduos nos diversos momentos do ciclo vital. Porém, apesar dessa área estar em crescente prosperidade em alguns países, as discussões a esse respeito ainda são incipientes no Brasil ${ }^{(3)}$.

Em quesito reconhecimento, apesar da enfermagem possuir papel fundamental desde o nascimento até a morte, essa profissão ainda é muito desvalorizada socialmente. Com o propósito de dar mais visibilidade aos enfermeiros a Organização Mundial da Saúde (OMS) lançou, em 2018, a campanha Nursing Now. Essa campanha visa aumentar e melhorar a disseminação de práticas eficazes e inovadoras na área da enfermagem. Acrescentado à esse movimento, o ano de 2020 surpreendeu a todos com a Pandemia de Covid-19, demonstrando cada vez mais como os profissionais dessa área são essenciais, e por isso foi declarado o Ano Internacional da Enfermagem ${ }^{(4)}$.

Diante da emergência da Covid-19, o isolamento social vem modificando as relações humanas, ao passo que desde os primórdios o Homem sempre viveu em sociedade, e baseou suas relações na coletividade, sendo constantemente influenciado pelo meio onde está inserido e as pessoas ao seu redor. Dentre os impactos na saúde, os profissionais que estão na "linha de frente" são, especialmente, suscetíveis aos reflexos do isolamento, exaustão física e mental, gerando ansiedade pelo risco constante de perder colegas e se contaminar $^{(5-7)}$.

Nessa ótica, o cuidado de enfermagem realizado na prática assistencial necessita ser reinventado sobre a maneira de transmitir informações, bem como acolher aqueles que precisam. As mídias sociais se configuram como uma alternativa para otimizar o compartilhamento de conhecimentos e reduzir as barreiras que obstaculizam a disseminação de conhecimento sobre a enfermagem de reabilitação(6).

Assim, este estudo se justifica pelo distanciamento social causado pela situação epidemiológica de pandemia, juntamente com a inevitabilidade de reinventar a forma de transmitir conhecimento, bem como pela insuficiência da enfermagem de reabilitação no contexto brasileiro e pelo impulso da valorização dessa profissão. Logo, o objetivo geral dessa pesquisa foi compreender o impacto do uso da mídia social, em tempos de pandemia, como instrumento para compartilhar conhecimentos sobre enfermagem, saúde e reabilitação.

\section{METODOLOGIA}

Trata-se de uma pesquisa de abordagem qualitativa sob - método da Análise Exploratória de Redes Sociais (ARS), realizado entre março e junho de 2020 , sendo o período da intervenção principalmente nos três primeiros meses, e a coleta de dados nos dois últimos meses. Esse método de investigação científica e exploratória consiste em uma abordagem oriunda da Sociologia, da Psicologia Social e da Antropologia (8). Essa metodologia permite que a interdisciplinaridade das áreas de conhecimento possa ter um dos seus múltiplos aspetos capturados e analisados ${ }^{(9)}$.

0 uso desse método viabilizar a análise e estruturação de um campo do conhecimento acerca da produção científica de uma área do conhecimento específica, constituindo como uma ferramenta complementar àquelas já empregadas nas análises bibliométricas ${ }^{(10)}$. Vale ressaltar que a ARS interessa à vários campos de conhecimento científico, à medida que compreende o impacto da mídia sobre a vida social ${ }^{(11)}$. De forma sistemática, o método de ARS é composta por quatro atividades sequenciais e cíclicas, a saber: 1 ) a definição mídia digital; 2) a manipulação da mídia digital; 3) a determinação de características estruturais; e 4) a inspeção visual ${ }^{(9)}$.

\section{Definição da mídia digital}

Dentre as opções de mídias sociais do grupo (Re)Habilitar já existentes, optou-se pela mídia denominada Instagram em virtude de sua gratuidade, facilidade de uso, oportunidade de construir vídeos, chamadas ao vivo e postagem de fotos (instantâneas ou permanentes). Aproximando as pessoas, o mundo globalizado é digital desde a implantação das mídias sociais no cotidiano das pessoas. Nosso grupo apoiou-se nesse paradigma e construiu o nosso perfil intitulado @rehabilitarufsc em 2017. O perfil global dos nossos seguidores é constituído de profissionais da saúde de diversas origens geográficas e disciplinares, abrangendo a temática da enfermagem, saúde e reabilitação. Conforme a linha de pesquisa do grupo, ampliamos os conceitos de enfermagem de reabilitação, atribuindo valor à transdisciplinaridade.

\section{Manipulação da rede}

A manipulação das redes implica extrair partes significativas da rede como subgrupos para fins de análise. Para isso é necessário compreender a necessidade de incrementar esforços às necessidades 
dos seguidores frente ao cenário de pandemia e isolamento social. Quando começamos a reconstruir o layout da página, em março de 2020 , questionamos os seguidores sobre os assuntos de interesse para abordar em vídeos ao vivo (Lives), postagem de informações temporárias (Stories) e indexação em Destaques ou postagens na página (Feed) em formato de vídeos permanentes (IGTV) ou imagens.

As provocativas aos seguidores para apresentarem temas de interesse ocorreu de duas formas: primeiramente foram elaboradas mensagens de impacto, claras e objetivas, postadas em formato de Stories, onde os seguidores poderiam responder diretamente as temáticas de inquietação. Em segundo momento, foi desenvolvido um documento online em formato de questionário que buscou compreender, profundamente, as motivações da participação dos seguidores ao nosso perfil. Esse questionário era acessado por link disponível na biografia da página, Stories e Feed, entre os dias 20 de abril à e 22 de maio de 2020.

A partir disso, no quadro 1 abaixo encontram-se as grandes temáticas levantadas pelos seguidores e abordados na mídia social:

Quadro 1: Principais temas abordados (Fonte: Autores)

\begin{tabular}{|c|c|}
\hline \multicolumn{2}{|c|}{ Principais temas abordados } \\
\hline Tema & Modo de abordagem \\
\hline Reabilitação & Vídeos + Lives \\
\hline $\begin{array}{c}\text { Enfermagem de } \\
\text { reabilitação } \\
\text { Enfermagem }\end{array}$ & Lives \\
\hline Acessibilidade & Imagens + Vídeos \\
\hline Deficiência & Vídeos + Lives \\
\hline Covid-19 & Vídeos + Lives \\
\hline Saúde Mental & Vídeos + Lives \\
\hline
\end{tabular}

Determinação de características estruturais da rede

As características estruturais das redes são aquelas que podem ser quantificadas por meio de métricas. Ou seja, é através das determinações estruturais que respondemos as seguintes questões: Como descobrimos o que nossos seguidores querem saber? Qual o nível de conhecimento dos nossos seguidores? Qual a melhor forma de transmitir a informação?

Para responder às interrogações elencadas, desenvolvemos Enquetes (inquéritos) no perfil do @rehabiltiarufsc postados nos Stories, entre o dia 20 e 28 de abril. As enquetes envolveram os seguintes eixos: 0 que é reabilitação? 0 que é acessibilidade? 0 que é deficiência? De que maneira o @rehabilitarufsc te fez pensar diferente? Essas perguntas foram respondidas pelos seguidores em forma de texto livre, oportunizando a expressão do conhecimento dos seguidores sobre temáticas centrais do perfil.
Não houve critérios de exclusão sobre as respostas dos seguidores, uma vez que todos aqueles que responderam ao questionário foram contabilizados como participantes da pesquisa, sem distinções de grupos. É válido lembrar que nossos seguidores são em sua maioria profissionais da saúde ou estudantes da área, porém há uma pequena parcela de não profissionais. Além disso, buscamos comparar com outras mídias sociais com objetivos semelhantes para construir nosso trabalho. Realizou-se uma busca nas mídias de grupos de pesquisa da área da Enfermagem, Reabilitação e Saúde para agregar valor ao layout do nosso projeto.

\section{Inspeção visual}

A inspeção visual da mídia social revela as características dos atores perante um grupo. Dessa forma, a visualização sistemática dessa rede demonstra conceitos e comprovações da efetividade do nosso esforço. Para mensurar isso, desenvolvemos questões de assinalar postadas nos Stories entre os dias 04 e 07 de maio. Perguntou-se sobre: a frequência que assiste os vídeos de IGTV; a frequência que assiste as Lives; como o perfil melhorou o enfrentamento durante o período de pandemia; como o perfil acrescentou novos conhecimentos; e como o perfil impactou no enfrentamento durante o período de pandemia.

Para a análise textual dos dados estratificados foi utilizado o Natural Language Processing (NLP), uma estratégia que une vários campos de conhecimento, como Computação e Linguística, possibilitando também a transformação de texto em dados estruturados. Esse instrumento realiza a tradução automática, reconhecimento de fala e sumarização de texto. Dessa maneira, tornou-se útil para a extração e interpretação de informação. As principais aplicações desse modelo analítico na área da saúde ocorrem em análise de opiniões e avaliação de impacto de intervenção. Após a execução da análise de dados, os resultados foram apresentados em forma de gráficos e em tabelas, de modo que pudessem ser analisados e discutidos em conjunto. ${ }^{(12)}$

\section{Condições éticas de pesquisa:}

A pesquisa faz parte de um macroprojeto intitulado "Cuidado de enfermagem de reabilitação como processo emancipatório", submetido na Plataforma Brasil e aprovado pela Comissão de Ética Pública, conforme CAEE $\mathrm{n}^{\circ}$ 02022918.5.0000.0121 e Parecer $\mathrm{n}^{\circ}$ 3.094.742, observando-se as recomendações da Resolução 466/2012, do Conselho Nacional de Saúde, para análise e liberação à realização da pesquisa. 0 anonimato dos participantes foi respeitado conforme as orientações éticas de estudos com seres humanos, sendo denominados "Seguidor", seguido de número sequencial.

\section{RESULTADOS}

O estudo envolveu duas fontes para a descrição de dados sociodemográficos, através do documento online 
e dados retirados da própria plataforma digital do Instagram. A estratificação dos dados foi realizada no mês de maio de 2020, contemplando o número total de seguidores de 1.049 indivíduos. A maioria são mulheres (81\%) com média de idade de 29,5 anos, profissionais ou estudante da área da saúde $(94,3 \%)$, sendo $2 \%$ de pessoas com deficiências declaradas. Os dados de gênero e faixa etária são detalhados nos Gráficos 1 e 2 a seguir:

\section{Género \\ $\square$ Mulheres $\square$ Homens}

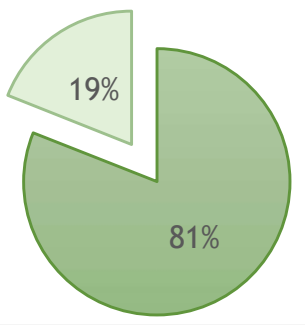

Gráfico 1: Análise dos dados sobre o gênero dos 1.049 seguidores (Fonte: Instagram)

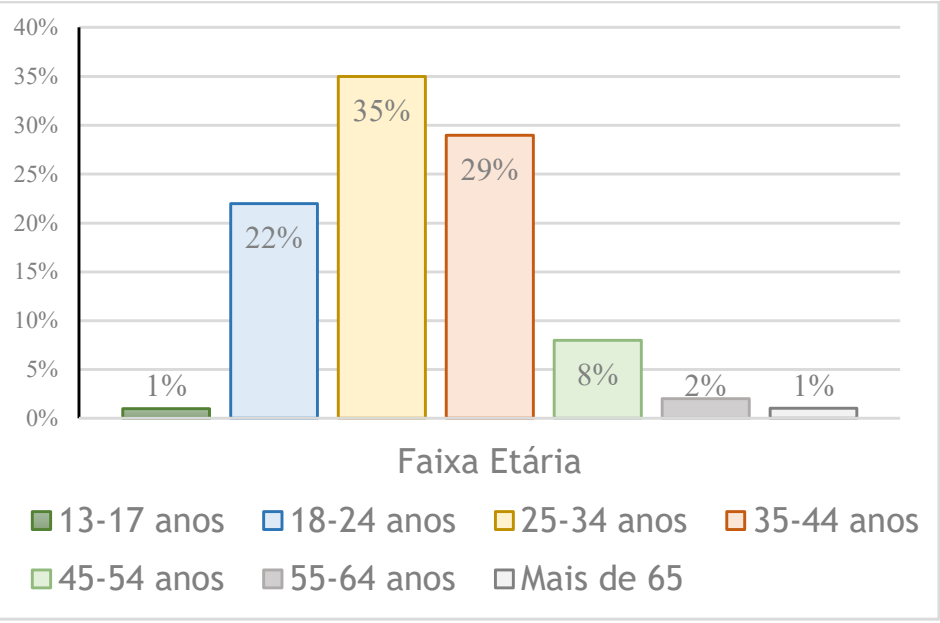

Gráfico 2: Análise dos dados sobre a faixa etária dos 1.049 seguidores (Fonte: Instagram)

A maior parte do nosso público é de origem brasileira (97\%), essencialmente da região Sul do Brasil, em especial do município de Florianópolis (41\%), contemplando também outros municípios do estado de Santa Catarina, como São José, Palhoça e Lages (9\%). Além disso, há seguidores internacionais de países como Portugal, Argentina, Suécia, Itália e Palestina.

Dentro da plataforma do Instagram, é possível desvelar medidas que mensuram a participação dos seguidores ao perfil. Agregando essas informações apresento o Quadro 2 que soma as informações supracitadas de forma sintética e organizada.

Vale recordar que de agosto de 2017 até março de 2020 foram publicadas 48 imagens no Feed, acrescentando pouca interatividade na página e alcance de 320 seguidores. A partir das nossas ações no perfil do Instagram, em meados de março de 2020 , nossa média semanal de Stories alcançou 65 postagens, diversas Lives, bem como já somam 87 publicações no Feed, envolvendo imagens e vídeos de IGTV. Dessa maneira pode-se perceber que o número atual de seguidores expressa um aumento de $227,8 \%$ em três meses de ações no perfil.

Quadro 2: Medidas semanais de participação dos seguidores no perfil do Instagram (Fonte: Instagram)

Medidas de participação do perfil do Instagram (avaliação semanal)

\begin{tabular}{|l|l|}
\hline $\begin{array}{l}\text { Dias da semana com maior } \\
\text { visualização }\end{array}$ & $\begin{array}{l}\text { Segunda a } \\
\text { Sábado }\end{array}$ \\
\hline Horários com maior visualização & 09 às 21 horas \\
\hline $\begin{array}{l}\text { Impacto da publicação nos } \\
\text { seguidores }\end{array}$ & $\begin{array}{l}5.355 \\
\text { visualizações }\end{array}$ \\
\hline Contas alcançadas & 657 contas \\
\hline $\begin{array}{l}\text { Impressões de seguidores e não- } \\
\text { seguidores sobre postagens }\end{array}$ & $\begin{array}{l}9.208 \\
\text { impressões }\end{array}$ \\
\hline $\begin{array}{l}\text { Interações (Curtir, comentar ou } \\
\text { compartilhar) }\end{array}$ & 251 interações \\
\hline Visitas ao perfil & 248 visitas \\
\hline
\end{tabular}

\section{Categoria 1: INTERATIVIDADE AO VIVO}

Os vídeos Ao Vivo em formato de Lives, compreendem uma forma interativa e dialogada para o compartilhamento de conhecimentos. A necessidade desse formato de apresentação surgiu do interesse dos próprios seguidores em assistir debates e apresentações individuais sobre temas que circundam a enfermagem de reabilitação. Somado a isso, as enquetes lançadas possibilitaram avaliar o nível de conhecimento dos nossos seguidores sobre assuntos relacionados à reabilitação, deficiência, acessibilidade. Essas enquetes lançadas nos Stories forneceram os seguintes relatos dos seguidores:

"Reabilitação é a habilidade de descobrir novas formas de viver" (Seguidor 01).

"A reabilitação é um processo educativo, essencial $e$ interdisciplinar, buscando de forma compartilhada, trabalhar as funcionalidades da pessoa, além de prevenir complicações e agravos, atingindo seu maior potencial físico, psicológico, social, vocacional e educacional” (Seguidor 02).

"Reabilitação visa a adaptação física, social e, sobretudo, melhorar a qualidade de vida. Ou seja, é promover a autonomia e reinserir o indivíduo no meio social" (Seguidor 03).

Pode-se perceber que os seguidores já apresentavam interesse em compreender o conceito de enfermagem de reabilitação, ao passo que entendiam a importância da especialidade, mas não relatavam a sua relação com a profissão de enfermagem. Além disso, abordam densamente questões como autonomia, saúde mental e vivência cotidiana como prismas do processo de reabilitação.

"Acessibilidade é um conceito amplo, que transcende as barreiras arquitetónicas" (Seguidor 04). 
"Acessibilidade envolve dispor de recursos promover a equidade $e$ atender as necessidades individuais" (Seguidor 05).

A temática de acessibilidade provoca inquietação nos participantes, ao passo que descrevem a mesma como uma barreira enfrentada pelas pessoas, provocando desvantagens na participação social. Referem o termo como uma necessidade para relações equânimes na comunidade, porém, não descrevem como isso ocorre na vivência diária.

"As deficiências englobam funções corporais somadas às barreiras que impedem a pessoa de participar" (Seguidor 06).

"Deficiência é uma característica. São barreiras que irão influenciar a inclusão da pessoa" (Seguidor 07).

O conceito de deficiência é percebido pelos seguidores como algo relacionado ao corpo e funcionalidade, que impacta essencialmente na participação dos indivíduos na sociedade e envolve barreiras que influenciam na exclusão das pessoas, impedem a liberdade e autonomia preconizada pela reabilitação.

Diante disso, focou-se esforços em atender as temáticas de interesse dos seguidores e explorar a enfermagem de reabilitação de forma transdisciplinar e integral. Foram desenvolvidas 30 Lives, tendo início no dia 27 de março e finitude no dia 29 de Maio de 2020. As temáticas abordadas foram: Reabilitação; Enfermagem de Reabilitação; Deficiência; Autonomia; Esperança; Teoria do Reconhecimento; Vivências de Enfermeiras na "linha de frente" contra o Covid-19; Dor e o uso de Práticas Integrativas e Complementares; Saúde Mental em tempos de Pandemia; Empatia; Cuidados de Estomaterapia no contexto da Reabilitação; Protetização; Realidade da Enfermagem de Reabilitação no estado de Santa Catarina; História da Enfermagem e da Reabilitação; Realidade portuguesa frente ao Covid-19; Enfermagem como ciência do cuidado; Síndrome de Burnout; Direitos das pessoas com deficiência no Brasil; Reabilitação da pessoa idosa.

Todos os temas supracitados foram trabalhados com um mediador que disparava perguntas, roteirizadas antecipadamente, ao convidado com expertise na área de conhecimento. O tempo total de Lives foi de 25 horas e 50 minutos. Essas Lives oportunizaram diálogos e reflexões, bem como a participação dos seguidores mandando perguntas no Chat disponível na própria plataforma. Além disso, ainda formulamos uma questão, postada em formato de Teste nos Stories, sobre a frequência que os seguidores assistem às nossas Lives. A resposta dessa pesquisa expos que $45 \%$ dos nossos seguidores assistem sempre as Lives, enquanto $36,3 \%$ assistem frequentemente e 18,1\% assistem raramente. A participação dos seguidores nas Lives pode ser vista através do Gráfico 3.

Por último, validou-se a pertinência e significância do conteúdo das Lives através de um questionário online disponível em formato de Link digital para os seguidores responderem quais as temáticas abordadas que mais atraíram sua atenção e ainda desejam aprofundar conhecimentos. Essa pesquisa mostrou que os seguidores se apresentam inquietos acerca dos seguintes temas: saúde mental na quarentena, eixos filosóficos da enfermagem de reabilitação, enfermagem de reabilitação frente à pandemia, formas de promover a autonomia e a participação na reabilitação em tempos de isolamento social.

\section{Número de Visualizações de Lives}
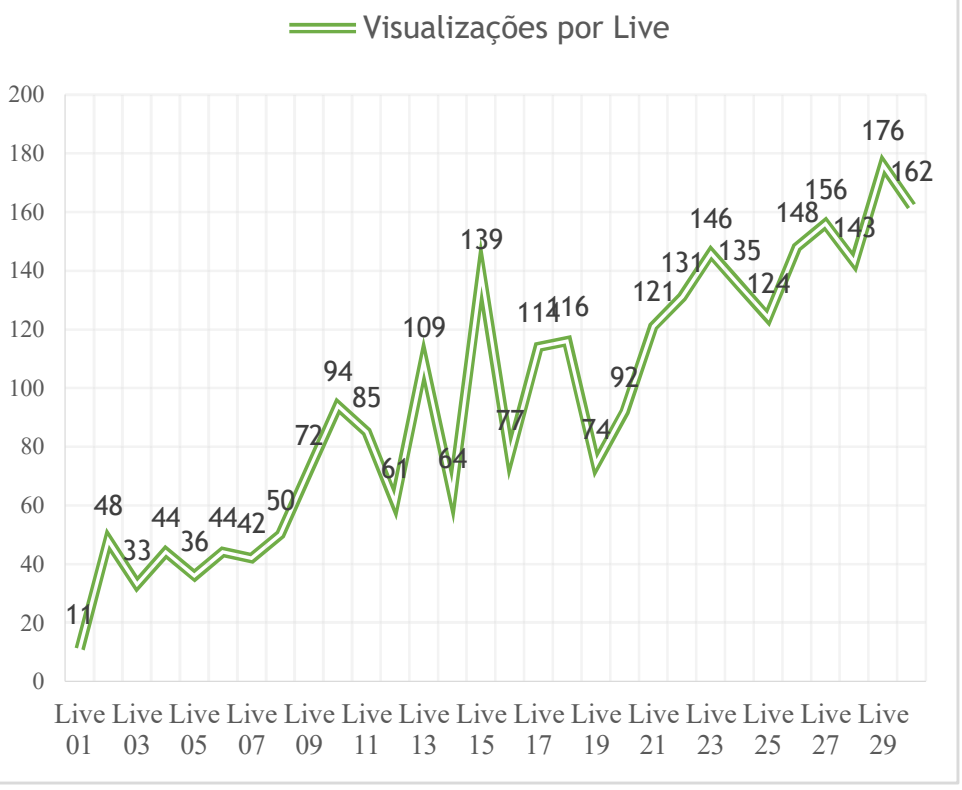

Gráfico 3: Número de visualizações de Lives realizadas em dois meses (Fonte: Autoras)

\section{Categoria 2: INTERATIVIDADE DIÁRIA}

Como meio de manter uma interação diária com os seguidores utilizamos o canal do IGTv, e as postagens permanentes ou temporárias (Feed e Stories). Mensalmente selecionamos tópicos para vídeos de segunda a sexta-feira, tendo totalizado 39 vídeos. Em sua maioria estes vídeos foram produzidos por nós ou por convidados, sendo que seus assuntos eram cuidadosamente pensados para ter relação com as Lives da semana ou com as datas comemorativas do mês.

Assim, os assuntos abordados foram: Orientação para atividades domiciliares; Saúde mental em tempos de Covid-19; Dicas de documentários, filmes, livros, aplicativos em saúde e cursos online; Projeto de extensão Consultório na Rua; Capacitismo; Empatia; Cateterismo intermitente limpo; Autismo; Meditação; Língua brasileira de sinais; Espondilite anquilosante; Prevenção contra Covid-19 para usuários de cadeira de rodas; Luta Antimanicomial; Conscientização sobre a LGBTfobia e História de Enfermeiras.

Adentrando critérios que validam a disseminação de conhecimentos, pode-se perceber que, ao final de dois meses, o impacto total dos vídeos postados no perfil totalizou 6.405 visualizações. Sendo que o vídeo com menor número de visualizações apresentou o total de 74 acessos, enquanto o vídeo de maior número de acessos apresentou 336 visualizações.

O Feed servia essencialmente como plataforma de divulgação para manter os seguidores a par do que a 
página oferecia. Assim, mensalmente era postado um calendário com todas as Lives do mês, ao mesmo tempo que cada Lives também era individualmente divulgada dias antes de acontecer. Além disso, todos os vídeos no IGTV eram também divulgados ali em formato de prévia.

As publicações em Stories visavam aumentar a interatividade e permitir um feedback dos seguidores para connosco. Por esta ferramenta, proporcionávamos aos seguidores a chance de indicar questões de seu interesse para serem trabalhadas e avaliarem nossa página. A menor quantidade de acessos em uma publicação temporária que obtivemos em 24 horas foi 59 visualizações, ao passo que a maior quantidade foi de 124 visualizações no mesmo tempo.

No dia 04 de maio perguntamos, em formato de teste, com que frequência eles acessam o conteúdo postado no IGTV, as respostas revelaram que $77,7 \%$ dos seguidores assistem sempre ou frequentemente, enquanto $16,6 \%$ assistem às vezes, e apenas 5,5\% nunca assistem. Ainda neste sentido, nos dias 29 e 30 de abril os seguidores foram indagados, agora em forma de enquete, de que maneira o @rehabilitarufsc os fez pensar diferente, e obtivemos a seguinte fala:

"Compartilhando conhecimentos através de Lives $e$ Posts." (Seguidor 08)

Além disso, a fim de impulsionar a visualização, as publicações temporárias mais relevantes foram divididas em categorias e postas em Destaques na página, tornando-as permanentemente disponíveis. Foram estas categorias e seus respetivos conteúdos: "Colabs", na qual estavam registros das Lives feitas com convidados; "Literatura", onde ficavam todas as indicações de artigos e livros feitas durante as Lives; "Publis", onde divulgamos as publicações científicas dos pesquisadores do grupo (Re)Habilitar; "Lives", na qual apresentamos resumos dos temas abordados nas Lives; "Grupo", onde os membros do grupo se apresentam em vídeos curtos; "Eventos", onde divulgamos os eventos promovidos pelo grupo; e "Projetos", onde explicamos um pouco sobre cada projeto de extensão realizado pelo grupo.

Durante o mês de maio utilizamos esses três espaços para incentivar ainda mais o reconhecimento da Enfermagem e da especialidade de Reabilitação. Toda nossa programação foi elaborada em comemoração ao mês da enfermagem: os vídeos de IGTV e Lives homenageavam enfermeiras e compartilhavam suas experiências. Bem como, foi abordado o a vivência de enfermeiros frente ao Covid-19. A comemoração do dia 12 de maio envolveu a participação de uma enfermeira especialista em reabilitação de Portugal, a qual relatou a história da profissão e como a profissão tem enfrentado a realidade da pandemia no cenário internacional. Além disso, lançamos uma campanha de valorização da Enfermagem frente à pandemia, intitulada "Nurse Challenge". Este desafio convidava os seguidores a gravar um vídeo de até dez segundos batendo palmas e marcar profissionais de Enfermagem.
Categoria 3: IMPACTO DA MÍDIA SOCIAL NO CONHECIMENTO SOBRE ENFERMAGEM, SAÚDE E REABILITAÇÃO EM TEMPOS DE PANDEMIA

Rememorando o objetivo central deste estudo, é inerente à pesquisa a necessidade de consolidar a mídia social como uma ferramenta que oportuniza o compartilhamento de conhecimentos sobre Enfermagem de Reabilitação, em tempos de pandemia. Diante disso, questionamos os seguidores se o perfil acrescentou novos conhecimentos, sendo que $96,9 \%$ dos participantes relataram ter apreendido saberes inéditos a partir dos diversos formatos que foram elaborados pelas autoras.

A expressão estatística do acréscimo de conhecimento corresponde aos dados citados no corpo do estudo, demonstrando que a mídia social assumiu um papel inovador no compartilhamento de saberes e possibilitou maior visibilidade ao contexto da especialidade de reabilitação no cenário brasileiro. Além disso, a divulgação de literaturas científicas agrega validade, confiabilidade e curiosidade ao nosso seguidor, despertando para a Enfermagem de Reabilitação pela intencionalidade de cuidado.

Outro fruto importante do estudo envolve a análise do impacto da mídia digital no enfrentamento do período de quarentena. Os seguidores foram questionados sobre como enfrentam a situação de Pandemia e se a mídia digital facilitou esse processo durante o isolamento social. O que se pode perceber é que $90,9 \%$ dos participantes relataram impacto da mídia digital no seu enfrentamento do dia-a-dia, à medida que o conteúdo programático serviu de trampolim para ultrapassar sentimentos tristes, assumindo novos conhecimentos de forma dialógica. A seguir são mencionadas algumas falas dos participantes acerca dessa questão:

"É importante saber que há informação segura e direta sobre a saúde, de fácil acesso e bem explicativo. Como tenho muito tempo livre nessa situação, me sinto melhor assistindo Lives de bom conteúdo. Sinto-me produtivo." (Seguidor 09)

"Acrescentou conhecimentos úteis para minha vida profissional e pessoal. Discutiu-se assuntos diversos e Coronavírus. Descobri a enfermagem de reabilitação e ampliei meus conhecimentos." (Seguidor 10)

"Ampliei minha visão sobre a reabilitação em vários aspetos. Acredito ser uma grande oportunidade que (in)felizmente o próprio COVID-19 nos trouxe, pois está aproximando pessoas para esse espaço de discussão $e$ aprendizado." (Seguidor 11)

É visto, a partir dos relatos dos participantes, que a enfermagem de reabilitação rompeu barreiras da academia e centros especializados, agregando conhecimentos novos e instigando o acréscimo de saberes. A enfermagem começa a conhecer um cuidado que apresenta um caráter de distanciamento social, porém aproxima as pessoas a construírem conhecimentos importantes para a trajetória profissional e pessoal. Nesse sentido, questionamos nossos seguidores quais as medidas que cada um tem encontrado para lidar com a situação do isolamento social, as respostas são expostas a seguir: 
"Tenho tentado manter uma rotina organizada, assisto pouco noticiário para evitar muitas notícias ruins, faço contato virtual com amigos e família, faço atividade física em casa, adoro ler, cozinhar, meditar e refletir sobre o que estamos vivendo." (Seguidor 12)

"Passo meu tempo lendo assuntos interessantes que surgem nas redes sociais, busco entretenimento $e$ relaxamento. Para adquirir conhecimentos, mesmo em tempos de pandemia, assisto Lives e cursos online." (Seguidor 13)

Diante disso, é possível perceber que as pessoas têm buscado, a partir das mídias sociais, medidas para enfrentar o estado de quarentena e isolamento social, considerando que a troca de conhecimentos e vivências fortalece nossa cidadania e agrega dignidade ao momento imerso em tanta tristeza e frustração global.

\section{DISCUSSÃO}

As mídias sociais necessitam ser compreendidas como espaços de convivência além da comunicação, os quais facilitam o desenvolvimento de habilidades úteis do cotidiano, reforçando seu uso como um instrumento educativo e mecanismo de atualização constante de conhecimentos científicos(13). Nesse contexto, a crescente preocupação com a qualidade de conhecimentos disponíveis propiciou a criação da Fundação de Saúde na Rede, em 1995 na Suíça, visando potencializar o uso das mídias como um instrumento de troca de conhecimentos, compartilhamento de experiências e aprendizagem ${ }^{(14)}$.

Porém, um fator desafiador no manejo das mídias sociais envolve a acessibilidade e prática inclusiva da plataforma, à medida que todas as pessoas, com deficiência ou não, deveriam conseguir utilizar o dispositivo de maneira igualitária. A participação de pessoas com deficiência no nosso perfil evidencia a fragilidade de acessibilidade, envolvendo falhas na conceção da página e edições. Corroborando para essa questão, é clara a necessidade de incentivar a participação da família e cuidadores, otimizando um conteúdo que contemple as necessidades diversas e atenda às exigências de diferentes realidades da reabilitação(14).

Questiona-se, ainda, o aspeto de que a ciência da enfermagem de reabilitação, por vezes, mesmo necessitando da interação pessoa-pessoa, é percebida como indiferente ou invisível na prática assistencial, considerando que o cuidado tem andado na contramão da sua própria essência. Nesse sentido, a mídia social possibilita um universo que aproxima a dimensão emocional, livre de julgamentos ou dilemas, esclarecendo dúvidas sobre o cuidado de enfermagem de reabilitação de forma humanizada(15). A rede social possibilita a reabilitação à consolidar as premissas éticas e profissionais de promover bem-estar e qualidade de vida através de orientações que potencializem o autocuidado ${ }^{(16)}$.

Nesta ótica, as mídias sociais assumem uma forma acessível de incrementar valor à intencionalidade de cuidar para a autonomia e independência do outro, atendendo à interface de entidades e movimentos políticos que visam consolidar coletivamente a especialidade no contexto mundial ${ }^{(17)}$. Corroborando à questão, a função do enfermeiro de reabilitação de reduzir as barreiras que obstaculizam a participação social, exercendo uma ação promotora da integração e participação cívica por meio da criação de espaços acessíveis e digitais ${ }^{(18)}$.

Logo, o cuidado de enfermagem de reabilitação, frente ao cenário de pandemia e isolamento social, visa elaborar estratégias de enfrentamento e autoconhecimento a partir de trocas e compartilhamento de conhecimentos pautados na evidência científica. Além disso, manter contato online com amigos e familiares e buscar novos saberes são práticas que melhoram a saúde mental e viabilizam a noção de pertencimento das pessoas ${ }^{(6)}$.

\section{CONSIDERAÇÕES FINAIS}

Nosso estudo mostrou que a situação de pandemia permitiu à enfermagem refletir sobre o cuidado que executa. Nesse sentido, 0 isolamento intensifica sentimentos como desamparo, tédio e solidão, fazendo com que a mídia digital surja como uma estratégia de manutenção socioafetiva para o enfrentamento desse contexto mundial. Ao mesmo tempo, esta representa uma nova forma de compartilhar conhecimentos sobre a enfermagem de reabilitação, ainda tão pouco disseminada e reconhecida no Brasil e no mundo.

\section{REFERÊNCIAS BIBLIOGRÁFICAS}

1. Lima MJ. O que é enfermagem. [São Paulo]: Editora basiliense; 2017. $105 \mathrm{p}$.

2. Geovanini $\mathrm{T}$, et al. História da enfermagem: Versões e Interpretações. 4th ed. Rio de JAneiro: Thieme Revinter; 2017. 105 p. 470 vol.

3. Fernandes C. S., et al. Produção de conhecimento em enfermagem de reabilitação portuguesa : scoping review. Jornal Health NPEPS [Internet]. 2019 Jan 01 [cited 2020 May 27];Artigos de Revisão:282-301.

$\mathrm{DOI}$ http://dx.doi.org/10.30681/252610103378. Available from: https://periodicos.unemat.br/index.php/jhnpeps/article/view $/ 3378$

4. Salvage J. Uma nova história da enfermagem. Rev Enferm Ref [Internet]. 2018;IV(17):3-12. Recuperado de: https: / / www.redalyc.org/articulo.oa?id=388256983001

5. Areosa SVC., Gaedkeo MA. A pandemia da COVID-19, o isolamento social e as revistas científicas. J Infect Control [Internet]. 2020 May 03 [cited 2020 May 27]; Cartas ao editor: 1-2.Available from: http://www.jicabih.com.br/index.php/jic/article/view/299/pdf

6. Mauch AGD, et al. A utilização das redes sociais digitais no cuidado psicossocial infantojuvenil, diante da pandemia por Covid-19. Health Residences J [Internet]. 2020 May 24 [cited 2020 May 28];1:41-61. Available from: https://escsresidencias.emnuvens.com.br/hrj/article/view/34

7. Medeiros EAS. A luta dos profissionais de saúde no enfrentamento da COVID-19. Acta paul. enferm. [Internet]. 2020 [cited 2020 May 28] ; 33: e-EDT20200003. Available from: http://www.scielo.br/scielo.php?script=sci_arttext\&pid=S0103 -21002020000100202\&lng=en. Epub May 11, 2020. https: //doi.org/10.37689/acta-ape/2020edt0003.

8. Nooy W, Mrvar A, Batagelj V. Exploratory network analysis with 
Pajek. Cambridge: Cambridge University Press, 2005.

9. Sacerdote HCS, Sampaio RB, Gonçalves MDP, Fernandes JHC. Utilização dos métodos de análise de redes sociais na avaliação das interações sociais em um ambiente virtual de aprendizagem. Int. J. Knowl. Eng. Manage. 2015 Out; 9(4): 108-128.

10. Ferreira TR, Silva ZKA, Neto JDP, Silva JMO. Redes sociais na comunicação científica. Revista ACB: Biblioteconomia em Santa Catarina. 2019 Nov; 24(1):564-577.

11. Baptista RS, Brito TDLV, Braun LL, Tenório JM, Pisa IT. Colaboração acadêmica em informática em saúde baseada em análise de redes sociais. J. Health Inform. 2019 Nov; 11(4): 99104.

12. Xavier F, Olenscki Jrw, Acosta Al, Sallum Mam, Saraiva Am. Análise de redes sociais como estratégia de apoio à vigilância em saúde durante a Covid-19. Estud. av [Internet]. 2020 [cited 2020 Nov 13];34(99):261-282. Available from: https://doi.org/10.1590/s0103-4014.2020.3499.016

13. Miller D, et al. Como o Mundo Mudou as Mídias Sociais? [Internet]. [place unknown]: UCL Press; 2019 [cited 2020 May 29]. 306 p. DOI https://doi.org/10.14324/111.9781787356542. Available from: www.ucl.ac.uk/ucl-press

14.Cintra MM, et al. Análise da acessibilidade, acessos e certificações das informações de um fórum virtual de saúde. Rev Port Enferm Reabil [Internet]. 2019 [cited 2020 Jun 1];2:12-20. DOI 10.33194/rper.2019.v2.n2.02.4538. Available from: https://www.aper.pt/ficheiros/revista/RPERv2n2.pdf

15. Figueiredo NMA, Machado WCA, Martins MM. Reabilitação: Nômades em busca de sentido para o cuidado da pessoa com deficiência adquirida. Editora CRV. 2018; 1(1) 320p. DOI 10.24824/978854442210.6. Available from: researchgate.net/publication/323090925_Reabilitacao_nomade s_em_busca_de_sentido_para_o_cuidado_da_pessoa_com_defic iencia_adquirida

16. Martins MM, Ribeiro O, Silva JV. O contributo dos enfermeiros especialistas em enfermagem de reabilitação para a qualidade dos cuidados.. Rev Port Enferm Reabil [Internet]. 2018 [cited 2020 Jun 1];1:22-30. Available from: https://www.aper.pt/ficheiros/revista/rperv1n1.pdf

17. Schoeller SD, et al. Breve panorama mundial da enfermagem de reabilitação. Rev Port Enferm Reabil [Internet]. 2018 [cited 2020 Jun 1];1:6-13. Available https://www.aper.pt/ficheiros/revista/rperv1n1.pdf

18. Pereira RS, et al. A intervenção do enfermeiro de reabilitação na promoção da acessibilidade. Rev Port Enferm Reabil [Internet]. 2018 [cited 2020 Jun 1];1:66-73. Available from: https://www.aper.pt/Ficheiros/Revista/RPERV1N2.pdf 